\title{
Research on the present development status of micro-nano manufacturing in Jiangsu
}

\author{
Lu Zaigui ${ }^{1, \text { a }}$, Liu Ye ${ }^{2, b}$ \\ 1 Economic and Information Commission of Jiangsu Province \\ 2 Information Eng2ineering College of Yangzhou University \\ aemail, b1424429761@qq, cemail
}

\section{Keywords: micro-nano manufacturing}

Abstract. This paper introduces thel distribution, development status and trend of micro-nano manufacturing, the main technical characteristics ,the domestic and international status of the core technology, as well as the advantages and disadvantages of industrialization and so on in Jiangsu. The countermeasures and suggestions for the general development of micro-nano manufacturing in Jiangsu are presented through the enterprise investigation, and the development of the micro nano manufacturing in Jiangsu is summarized and prospected.

\section{Introduction}

The national long-term science and technology strategic development planning study pointed out that the" nano technology and micro system "is the future strategy in the field of high technology and an important direction of Industrialization of high and new technology, is the most potential for development of high technology in the 21st century. China manufacturing 2025 Jiangsu action plan will include "micro-nano manufacturing" in the field of international forward-looking extreme manufacturing technology and equipment. Owing to the distinctive characteristics of the micro scale, mass, low cost, Micro-nano devices and systems play a great role in promoting the modern production and life ,for traditional industry upgrading to achieve leapfrog development opportunities and provides the opportunity for the development of the related traditional industrial upgrading .it also spawned a number of emerging industries and has become one of the fastest growing industries in the world. widely used in the automotive, petrochemical, telecommunications and other industries, it expanded rapidly to the environment and security, medical and health fields at present, and in the new energy equipment, semiconductor lighting engineering, flexible electronics, optoelectronics and other aspects it also has important application prospect. With the application of micro-nano technology continues to expand, an opportunity for the development of related traditional industries to upgrade is provided, and it spawned a number of emerging industries so that it has been one of the fastest growing industries in the world.

With micro-nano manufacturing problems of basic science research continued to deepen, the scale involved expaned from macro to meso, micro and nano , as well as parameters developing from conventional to unusual or extreme, and it develops from macroscopic and microcosmic to micron and nano scale transition and mutual coupling with structure dimension from $2 \mathrm{D}$ to $3 \mathrm{D}$. manufacturing process and object relates to nano / micro / macro cross scale, scale and interface / surface effects accounted for a leading role. Micro nano manufacturing involves multiple disciplines such as light, machine, electricity, magnetism, biology and so on and a comprehensive study of multi-media field and multi field coupling is needed. As micro-nano devices tend to be smaller scale, higher efficiency and the diversity of materials, the machinability, measurement and characterization of materials have become the key issues. Overall, the trend of the micro-nano manufacturing technology development has many characteristics. its manufacturing scale is more small, its theory is richer, and manufacturing technology is more integrated as well as more discipline overlapping seepage ,furthermore, its application fields is more widely.

The main characteristics of the development of micro-nano manufacturing in China: (1) Basic research results is highlight .The team of micro nano science and technology research center of Jiangsu University took the lead in the country to carry out the basic research of micro mechanical 
design, achieved with the international leading level research, greatly promoted the development of micro machinery research in China, led by professor Ding Jianning in Jiangsu and the colleague experts think "it could be state of art in our country and expand new areas "[1,2] (2) it has achieved important theoretical breakthrough State Key Laboratory of tribology in Tsinghua University carried out fruitful work, explained the causes of frictional interface atoms unstable beating theoretically as well as conditions and the energy dissipation mechanism and developed chip micro friction tester. The Key Laboratory of design and manufacture of micro nano Bio Medical Devices in Jiangsu, led by Yi Hong, developed micro and nano medical device products with independent intellectual property rights and breaking the monopoly of foreign products. (3) Manufacturing technology is international leading. In the field of micro-nano operation, assembly and packaging technology, it has achieved a series of breakthroughs and the integration of optical, mechanical, electrical, biological, chemical and other complex micro and nano systems. Led by academician Zhu Di ,"electrochemical fabrication technology "has made a number of international advanced level of research results in high performance electroforming technology, precision electrochemical machining, micro and nano electrochemical machining etc. (4) Scientific research is rapidly increasing. A lot of work has been carried out in the mechanical characteristic test of micro component by Institute of mechanics of Chinese Academy of Sciences, Xi'an Jiao Tong University, Shanghai Institute of micro system and information technology, North University of China, Tianjin University, and Dalian University of technology.[3-8](5) it involved in a broad area. Micro-nano devices and systems have an important application field of industrial and production, medical and health, environment and safety industry ,involved in the field of science and people's livelihood, Micro-nano friction, wear mechanism and friction reduction strategy, batch, high performance and combination with nano and bio technology is the focus and the leading edge of the development of micro-nano devices and systems[9-13] .Microfluidic devices are an important branch of the micro-nano system, when the fluid channel is small to a certain degree, the mechanism and the external performance have many differences with the macro fluid. At present, micro fluid has become a hot research topic in the basic research[14-18].

\section{development status of micro-nano manufacturing in Jiangsu}

Jiangsu is an important province of Wiener manufacturing industry with complete product range. it formed a relatively complete industrial system, mainly including: MEMS products design and manufacturing, Manufacturing and system development of micro and nano processing equipment , Parts manufacturing in semiconductor processing equipment, related components manufacturing of micro and nano electronic devices, processing of micron powders .

MEMS device product design and manufacturing

In the "Tenth Five Year" period ,MEMS was officially included in the 863 major projects, furthermore, benefit from Education revitalization plan of the Ministry of education, the Chinese Academy of sciences knowledge innovation system, the Fund Committee and the Ministry of science and technology new projects as well as local and corporate investment, its total funding is approximately 5 million RMB. China has made considerable progress in the research and development of MEMS, many achievements have been carried out industrial applications, signs are as follows: micro inertial measurement unit and unit device obtained military applications; and a large number of micro sensor is used as the Shenzhou series of spacecraft control system; a variety of sensing element is for civil products; biological chip, blood biochemical detection system and smart pills and intelligent endoscope mirror started to be used in clinical practice. According to incomplete statistics, there are more than 120 units in the country to carry out research and development of MEMS[19].

Jiangsu is an important base for traditional microelectronics industry, with good conditions for the development of the MEMS industry and a plurality of integrated circuit production line. Some enterprises have international competitiveness in high-end products, pressure sensor, acceleration sensor, and has strong ability of independent research and development. In many sensor production companies, Nanjing Gao Hua Polytron Technologies limited liability company, Kunshan Yu Bin 
electronic technology limited liability company, Chengdu Hong Sheng technology limited liability company, and some scattered manufacturers develop better in the high precision sensor . As a high precision sensor, its main technical indicators are often harsh and complex. the same type of sensor also depends on the specific circumstances For high precision accelerometer, in addition to the Nanjing high technology, there are very few domestic enterprises specialized in the research and production; and for high precision pressure sensor, Kunshan Yu Bin electronic technology limited liability company begins to take shape based on the main technical indexes and foreign similar initial scale.

Ultra compact single chip thermal type (Thermo) acceleration sensor ,made by MEMSIC semiconductor (Wuxi) limited liability company based on standard CMOS technology, use standard CMOS integrated circuit technology of single chip integrated MEMS and ASIC circuit with small volume, light weight, low cost and batch production.It is widely used in mobile consumer electronics products (such as mobile phones) and high-end sensor, such as automotive electronics, industrial applications. MEMSIC triaxial single chip MEMS magnetic sensor has a $100 \%$ independent intellectual property rights, using the technology of MEMS and CMOS standard scale integrated circuit, with the advantages of small volume, light weight, low cost and batch production, and can integrate with IC system or extended integration of other MEMS sensors .The sensor of the technical indicators reached the international advanced level, which fills the gaps in this field in China, and will play a positive role in supporting the national MEMS industry and the corresponding automotive and consumer electronics industries development. MEMSIC semiconductor single chip magnetic sensor is mainly used in many fields of aerospace, automotive, industrial, consumer etc.. Automotive, consumer electronics and mobile phones accounted for about $70 \%$ of the market share of magnetic sensing applications. Nanjing Gao Hua Polytron Technologies limited liability company is to develop high reliable MEMS sensor and sensor network engineering , as a national high-tech enterprise, which launched sensor (Union) network industry alliance in Jiangsu. It is Nanjing MEMS sensor Engineering Technology Research Center and Jiangsu province enterprise graduate student work station. Its typical products include capacitive micro accelerometer, wafer level vacuum packaging of high precision capacitance type pressure sensor. In particular, the sensor that is made by the independent research and development performances stability in the range of -50 -125 with anti-interference and good stability (within 30 days), breaking the technical embargo of the developed countries. Due to historical reasons, Famous companies from the United States and Europe occupy the top in miniature and high frequency dynamic pressure sensor and other high-end products. although the high-end manufacturing itself is not a mass product ,enterprise scale is not large. Because of its importance, it is important to the promotion of military equipment, high-end ritual significant. Micro pressure sensor of the army enterprise is the United States Kulit (kulite) company. the minimum size of the product is $1.7 \mathrm{~mm}$ in diameter and the thinest product is $0.64 \mathrm{~mm}$. Shuangqiao sensor company's minimum product is $2 \mathrm{~mm}$ in diameter, the thinnest is $1 \mathrm{~mm}$. It basically reached the international advanced level, which make a contribution for our country. however, there is a certain gap in the performance and variety of complete between products and it need to work hard. Right now, for example, in high dynamic measurement of the sensor mainly monopolist is Kistler and PCB. Table 2.1 is the comparison of Shuangqiao sensor company and the two companies. It can be seen that the company is obviously superior to the key parameters in the natural frequency and the rise time, and its high dynamic key technical indicators have reached the international leading level.

Table 2.1 comparison of the product performance index of Kunshan Shuangqiao sensor company and Kistler company and PCB

\begin{tabular}{clcc}
\hline unit & Shuangqiao sensor & Kistler & PCB \\
\hline \multirow{2}{*}{$\begin{array}{c}\text { Semiconductor silicon } \\
\text { technology }\end{array}$} & $\begin{array}{l}\text { pressure resistance } \\
\text { principle and fully flush } \\
\text { structure with flat back } \\
\text { pressure on the back } \\
\text { natural }\end{array}$ & $\begin{array}{c}\text { Piezoelectric quartz } \\
\text { and Flush package }\end{array}$ & $\begin{array}{l}\text { Piezoelectric } \\
\text { piezoelectric or flush } \\
\text { package }\end{array}$ \\
\hline
\end{tabular}




\begin{tabular}{|c|c|c|c|c|c|}
\hline \multicolumn{6}{|l|}{ frequency } \\
\hline $\begin{array}{l}\text { corresponding } \\
\text { time }\end{array}$ & $0.1 \mu \mathrm{s} \sim 1 \mu \mathrm{s}$ & $4 \mu \mathrm{s}$ & & $2 \mu \mathrm{s} \sim 4 \mu \mathrm{s}$ & \\
\hline $\begin{array}{l}\text { Available } \\
\text { bandwidth }\end{array}$ & 1/3 Natural frequency & $\begin{array}{c}1 / 10 \\
\text { frequency }\end{array}$ & natural & $\begin{array}{c}1 / 10 \\
\text { frequency }\end{array}$ & Natural \\
\hline $\begin{array}{l}\text { Anti strong } \\
\text { infrared } \\
\text { interference }\end{array}$ & $\begin{array}{ll}\text { gold } & \text { diffusion } \\
\text { composite } & \text { machine } \\
\text { sputtering metal } & \text { screen } \\
\text { and shield design }\end{array}$ & no & & no & \\
\hline
\end{tabular}

micro-nano processing equipment manufacturing and system research and development

Jiangsu micro-nano processing equipment manufacturing and industries related to the system are mainly concentrated in the industrial park in Suzhou .Suzhou Institute of nano technology and nano bionics of Chinese Academy of Sciences (hereinafter referred to as Suzhou Institute of nano) achieved a seamless transition from the microelectronic technology to nano electronic technology; it used high precision nanomaterials and technology means to improve the traditional microelectronic products manufacturing process and the performance of integrated circuit products, especially the reliability of microelectronic products. Suzhou new nano crystal photoelectric limited company is the first to have a complete industrial chain of enterprise innovation ,from graphical to substrate to extension to chip to package to lamp assembly, in the control of InGaN Quantum Dots growth and LED efficiency droop with high power, LED heat radiating mechanism design, it made a number of research results . the maximum temperature of the chip packaging process must be lower than $280^{\circ} \mathrm{C}$, less than $10 \mathrm{~s}$ and main wavelength measurement error must be $+0.5 \mathrm{~nm}$.

Suzhou Navier Technology limited company put attention to the growth and development of nitride materials with high quality and large size, provide all kinds of Gan materials for Industry and research institutions and is first gallium nitride substrate chip suppliers in China. Suzhou Diener precision equipment limited company is mainly engaged in MEMS sensor packaging and testing equipment research and development and can provide customized packaging and testing automation system design for enterprises. it provide complete solutions to realize the batch manufacturing. For example, tensile testing equipment of independent research and development is specifically designed to test various lead strength test equipment and can adapt to the PCB board, dual in-line tube shell, dip, cob and other packaging structure of wire operation. Its positioning accuracy is $5 \mu \mathrm{m}$, visual recognition accuracy is $10 \mu \mathrm{m}$, and precision measuring degree can reach $0.001 \mathrm{~N}$

As a new field, Nano imprint lithography equipment's domestic development is relatively slow and the domestic nano imprint lithography equipment and supplies often relied on import. In recent years, although there are some companies providing such products, more being direct introduction of foreign equipment, not introducing key technologies, and enterprises with independent intellectual property rights is even more rare. Suzhou optical rudder micro-nano technology limited company is mainly engaged in nano imprint lithography equipment, nano imprint template and nano imprint lithography, and provide nano imprint lithography and micro nano processing solutions. The nanoimprint equipment mainly has four kinds: micro contact type nano imprint equipment, thermal and UV nanoimprint equipment, UV flexible die nano imprinting apparatus and hot embossing and UV imprint various nano imprinting apparatus alignment; the nano imprint template includes large area nano line shaped template, large area of nanopores and columnar template and nano imprint template; the nano imprint lithography glue products are mainly for nil series nano imprint consumable products. Its products' $\mathrm{R} \& \mathrm{D}$ and production is mainly facing to the customer .As an example, its large area of nanopores and columnar template's area is $1 \sim 10 \mathrm{~cm}^{2}$ and size resolution can reach the minimum $30 \mathrm{~nm}$. The minimum sample period of porous structure is $70 \mathrm{~nm}$, the highest aspect ratio is 3 and minimum sample period of the columnar structure is $100 \mathrm{~nm}$.

parts manufacturing in semiconductor processing equipment

International semiconductor equipment's global procurement need is about \$200 billion, mainly came from chip manufacturers and vendors supporting in Asia, South Korea, China Taiwan, Japan, mainland China, Singapore and the United States.And these devices, especially high-end chip 
production depends on some advanced equipment and production technology, which is on the control of the United States and Japan and other western developed countries. With the growing demand for high-end semiconductor products in China, the development of high-end semiconductor equipment has become a the urgent task on national security and market development .

At present, the leading maker of the large scale integrated circuit etching machine is the United States AMAT company, Japan TEL company and the United States LAM company. AMAT and TEL2013 were integrated and the combined AMAT-TEL chip equipment sales reached $\$ 32$ billion, accounting for the 1/4 total global output of the chip. Chinese Micro company has built a capacity of one billion U.S. dollars and the next five years is expected to produce 100 units and sales of 2-3 billion.

Pioneer Semiconductor Technology limited company to achieve a set of precision machining and surface treatment as one of the semiconductor micro nano processing equipment parts manufacturing .The development work is in the groundbreaking in semiconductor processing chamber $(14 \mathrm{~nm}$ process chamber), cavity heater and electrostatic chuck ( 8 inch) in China.Its semiconductor processing equipment parts in the semiconductor equipment limited company, North Microelectronics limited company is the best in the world's global component procurement projects.Pioneer $\mathrm{Co}$ is in the top four in the global procurement among 350 micro Semiconductor Equipment Co., Ltd., the second of the supply of North Microelectronics Co., Ltd. Taiwan exports of equipment parts

Except for the Shanghai Songjiang, Foxconn, pioneer Semiconductor Technology Co., Ltd is only the only company similar with international standards of large-scale integrated circuit plasma etch chamber in technology in our country, as a professional manufacturer of integrated processing and table processing.Project products have a good cooperation agreement with domestic large customers (micro Semiconductor Equipment Co., Ltd., North Microelectronics Co., Ltd.) with the product of corrosion resistance, high breakdown voltage, reliable quality and excellent performance. In particular, the orrosion resistance performance the surface treatment part of the component is high, whose thickness of the oxide layer is uniform. The service life of the product is prolonged, and the cost of the user is saved. Pioneer Semiconductor Technology Co., Ltd. has reached a very high level, enough to comparable to similar foreign advanced technology in the processing of semiconductor equipment parts manufacturing. It is in the domestic leading position ,whose key technology is surface treatment technology, extrusion honing micro manufacturing process,.

micro- nano devices manufacturing

At present, the domestic production of the mask is mainly based on etching technology. although this technology is more mature, restricted by the import material, so the special production of domestic mask has long stalled. Life in common mask is only made by some metal products company, such as Beijing Dongfang Huawei Technology Co., Ltd., Shenzhen Hong Yesheng metal product Limited company, etc., whose production level has reached the top level of ordinary metal manufacturing industry but still not high-end.At present, in the metal etching processing industry, the development of Shenzhen beaconton Electronic Co., Ltd is in a mature.. the minimum stable processing microporous can reach $0.1 \mathrm{~mm}$ and minimum thickness of the product can reach $0.03 \mathrm{~mm}$, the highest precision can reach $+7.5 \mathrm{~m}$. It has been close to the highest level of etching technology,.

The main products of Kunshan, Jiangsu Yun Sheng Ji Photoelectric Technology Co., Ltd. are high precision metal mask template for OLED deposition, metal mesh plate for photovoltaic solar screen silver paste printed .Its technological achievements originate from the National 863 project named " the development of high precision steaming plating mask plate". at present, the company has completed the research of the steaming plating mask for the PMOLED, and have the production capacity, possessing strong technological foundation to undertake the development of AMOLED.The core technology is the electroforming technology with advantages of high precision and arbitrary thickness (more than traditional $0.04 \mathrm{~mm}$ ), trapezoidal natural taper, smooth hole wall, high precision, more high aperture ratio than an etching reduction technology can realize products and other .Table 2.2 is the comparison of main technological parameters of Yun Kunshan Sheng Ji products and 
international manufacturers to find that the manufacturing precision and the tension and the network sag has reached the international advanced level

Compared with domestic counterparts, OLED first project production line of Anhui Dafu Photoelectric Technology Co. Ltd. has been officially put into operation. It is understood that Dafu heavy industries, Dafu photoelectric project are invested and built by Anhui Dafu Heavy Industry Technology Co., Ltd. with 15 million yuan, whose main construction contents include 3 production line of metal mask plate membrane of active organic light emitting display (AMOLED) evaporation, annual production capacity of super fine metal mask plate membrane being expected to reach 6000 sets, flexible devices (wearable electronics) 500 million pieces, precision electronic hardware components 5000 million, an annual output of 1000 sets of intelligent industrial robots, and annual output of mobile communication base station antenna reaching 70 million. Shanghai Hui and photoelectric Co., Ltd. is a high-tech company specializing in the production of small and medium size AMOLED display and the next generation of display technology. The company is currently the first domestic and most perfect and the most advanced 4.5 generation low-temperature polysilicon (LTPS) AMOLED production line, with large-scale production capacity

Table 2.2 comparison of main technical parameters of metal mask for OLED evaporation between Kunshan and international manufacturer

\begin{tabular}{|c|c|c|c|c|c|}
\hline Index & DNP & TOPPON & & $\begin{array}{c}\text { Allow } \\
\text { appreciation }\end{array}$ & \\
\hline Panel size & $450 \mathrm{~mm} \mathrm{X} \mathrm{550mm}$ & $\begin{array}{l}450 \mathrm{~mm} \\
550 \mathrm{~mm}\end{array}$ & $\mathrm{X}$ & $\begin{array}{c}450 \mathrm{~mm} \\
550 \mathrm{~mm}\end{array}$ & $\mathrm{X}$ \\
\hline $\begin{array}{l}\text { Open } \\
\text { position } \\
\text { precision }\end{array}$ & $\pm 5 \mu \mathrm{m}$ & $\pm 5 \mu \mathrm{m}$ & & $\pm 5 \mu \mathrm{m}$ & \\
\hline $\begin{array}{l}\text { Open } \\
\text { position } \\
\text { precision }\end{array}$ & $\pm 3 \mu \mathrm{m}$ & $\pm 4 \mu \mathrm{m}$ & & $\pm 3 \mu \mathrm{m}$ & \\
\hline $\begin{array}{r}\text { Stretch } \\
\text { mesh sag }\end{array}$ & $\leq 120 \mu \mathrm{m}$ & $\leq 150 \mu \mathrm{m}$ & & $\leq 100 \mu \mathrm{m}$ & \\
\hline
\end{tabular}

In the share of the AMOLED market, Samsung is undoubtedly the industry's leading enterprises with the advantage of Accounting for 9 of the global market share In fact, Samsung lead the AMOLED market boom until 2009 GALAXY phone were hot. As a result of the existing LCD in the former, although the initial development of OLED is not very smooth, PMOLED (passive matrix OLED) is mainly used for mobile phone, automotive, industrial applications and other markets; And at present, the world has more than 100 research institutes and enterprises to invest in the development and production of OLED, including the global industry giants, such as Samsung, LG, SONY and other companies.

micron powder materials processing

Micron powder material is mainly used for conventional powder metallurgy and injection molding, iron core, diamond tools, diamond catalyst, nutrition iron supplementation, microwave absorbing materials.

Among them, micron carbonyl iron powder is widely used in powder metallurgy, metal powder injection molding, powdered catalyst of synthetic diamond, diamond tools and hard alloy product of binder, high frequency and high quality factor, high permeability, low power soft magnetic materials, microwave absorbing camouflage material, electromagnetic compatible devices, $\mathrm{Mr}$ (magnetic damping), nondestructive flaw detection, magnetic inks, iron deficiency for the crowd of iron supplement etc..

The main parameters and characteristics of micron carbonyl iron powder made by Jiangsu superfine metal powder Co., Ltd. includes that the average particle size is 3-3.5um and oxygen content is less than or equal to $0.2 \%$, carbon content is less than or equal to $0.7 \%$.It has high purity, does not contain harmful heavy metals and contain only a small amount of $\mathrm{C}, \mathrm{N}$, O ; Except for fine 
particle size and narrow distribution, good sintering activity; powder into spherical and good fluidity, its accumulation slope is small and particle profile is concentric onion like layered structure etc..The company achieved the advantage of the synthesis of short cycle, high yield, the pyrolysis of intelligent, controllable, the formation of independent intellectual property rights of the process and equipment system. Its production scale is the country's largest, with the domestic leading technology level.

Only three company ,including BASF in Germany, the SINTEZ in Russia, the ISP in United States, product carbonyl iron powder on the international and its technical level is basically equivalent as well as product application surface.Because the product is widely used in national defense and high-tech industry, its production technology, equipment, scale have not been reported .Only some scattered and vague propaganda reports, and sporadic and simple product promotional materials printed by domestic agents published for civilian can be retrieved.The development and production of carbonyl iron powder in China has a history of nearly 40 years, but it has not been in a scale with backward technology and equipment, low production, unstable quality and narrow application, mostly relying on imports. Jilin Jien nickel industry is domestic listed companies. It is more speculation and the product quality is not stable. 857 original nuclear industry factory, Shaanxi Xingping chemical fertilizer plant has small quantity production, as two Western military industrial enterprises, whose total annual production isless than 200 tons; Guangdong Zhongshan Yue Dragon (Jiangxi Yue is a company with less than 300 tons annual production .Because of the system and the location, for decades, the process is small and obsolete with no technological progress. The production is of small scale, long reaction cycle, low yield and low quality and stability, etc

\section{conclusions and suggestions}

Overall, relative to the developed countries ,micro nano manufacturing industry is in the primary stage in Jiangsu. micro nano manufacturing equipment is mainly imported, lacking of talents for research and development and equipment input.Lacking of enterprise, industry and national standards, the industry chain is not complete, especially the lack of downstream industries, resulting in micro nano manufacturing low demanding for the quality of related products, so as to make the industry chain lack economic benefits leading to the loss of personnel, equipment and capital orientation. The talent strength of the enterprise is not strong, even no research and development department. Mainly by individual combat mode, it lacks research cooperation with universities and Research Institute; part enterprise of a certain innovation ability is too small and its degree of automation is not high. In view of the present situation of micro nano manufacturing industry in Jiangsu, the following suggestions are put forward:

(1) In the point of view of the micro nano manufacturing industrial structure, micro nano manufacturing industry design and manufacture of MEMS device as the main body with a certain industrial base in Jiangsu. Part of the products fill the domestic blank and performance of a small number of products is in the international leading level with higher share in the domestic product. On the basis of this, suggestions that it is necessary to increase MEMS device design, manufacturing and $\mathrm{R} \& \mathrm{D}$ equipment, fund and personnel input are given to make MEMS design and manufacturing industry in Jiangsu become the domestic first-class, and international advanced level characteristic industry industry, driving a whole the development of micro nano manufacturing industry. In addition, it is recommended to increase the micro nano manufacturing equipment and the R \& D investment of related parts and components, improving domestic equipment market share of micro-nano manufacturing, in order to reduce the cost of micro nano manufacturing, as strong support for a whole micro nano manufacturing industry in our province and even in our country.

(2) It is necessary to increase the investment of micro nano manufacturing industry fund project and guide micro nano devices and systems research and development boom, to achieve ways to solve key technical problems and to increase industry and national standards of the micro nano manufacturing related products.Due to the late start and the not mature technology and lacking the investment of capital and talent, Domestic micro nano devices has still a certain gap in terms of 
performance and foreign large quantities of automation products. Therefore, we should start from the fund project investment, attracting research personnel into research and development and technical research, accelerate the transformation of research results, increase the standards of enterprise, industry or national, in order to enhance the competitiveness and credibility of products.

(3) It is suitable that downstream industry demand promote the development of micro nano manufacturing industry chain. Current international products related to micro-nano technology mainly includes automotive electronics and consumer electronics products. the electronic products consumption is dominated by imports. imports of micro nano devices and system has excellent performance but expensive and domestic micro nano technology products are cheaper. in line with the industry standard, to improve the competitiveness of domestic micro nano devices product and expand the product demand could give the enterprise innovation to rise profits .

(4)It is necessary to input into the construction of semiconductor processing test center. Micro nano processing equipment, in the high-end of Micro nano manufacturing industry, in the short term is difficult to achieve complete localization and industrialization, and semiconductor processing and testing process of micro nano manufacturing process has an important role in micro and nano device design, system and equipment research and development, micro -nano manufacturing key technology research and even become a part of the business development constraints. Therefore, it is of great significance to set up the semiconductor processing test center, to realize the sharing of equipment resources, and to the development of micro nano manufacturing industry in our province and even in the whole country.

\section{References}

[1] Ding Jianning, Meng Yonggang, Wen Shizhu. Size effect of Polycrystalline silicon micro cantilever beam fracture failure strength [J]. China Mechanical Engineering, 2001, 12 (11): 1228 1231

[2] DING Jianning, MENG Yonggang, WEN Shizhu. Specimen size effect on mechanical properties of polysilicon microcantilever beams by deflection using nanoindentation. Materials Science and Engineering B., 2001, 83(1-3): 42-47.

[3] Mei niansong, Huang Qing'an the online test of MEMS film transverse rupture strength--a thermal driving method [J]. Micronanoelectronic technology, 2003 (7 / 8): Sweden

[4] Wu Hao, Yu Yonggang, Cai Jun Su,etc. test method of Fatigue property of polysilicon thin film [J]. Harbin Industrial University Journal, 2006, 38 (4): 592-595.

[5] Denggang. Measurement of Micro material mechanical property [D]. Shanghai: Shanghai Institute of Microsystem and information technology, 2003

[6] Jiang Zhuangde, Wang Hairong, Zhao Zexiang, et al. Micro mechanical mechanical properties tester: China, 00226180 2000-12-29. [P].

[7] Zhang Taihua, Yang Yemin, Zhao Yapu, et al. Progress in mechanical properties of.MEMS materials, [J]., 2002, 32, (4): 545-562.

[8] Su Caidiao, Wu Hao, Guo Zhanshe, et al. Test system of Mechanical properties of single crystal silicon micro component [J]. mechanical strength, 2005, 27 (4): 456-459.

[9]Li Zhijun, , Leng Yongsheng, Zou Kun, et. experimental study of surface force apparatus and solid surface micro contact mechanism [J]. Tribology, 2000, 20 (5): 336-339.

[10]Zhang Xiangjun of, Meng Yonggang, Wen Shizhu The AFM experimental study of MEMS microcantilever structure deformation rules [J]. Mechanical science and technology, 2005, 24 (8): 966-968.

[11] Shi Hongsheng, Wang Hui, Hu Yuanzhong. Design of elastic cantilever beam friction force measuring mechanism [J]. mechanical science and technology, 2004, 23 (11): 1327-1330.

[12] Tang Zhenan, Li Xin, Xu Jun. Preparation and characterization of diamond like carbon films for micro electro mechanical systems [J]. Journal of materials science, 2004, 18 (6): 582-586

[13] Qing Tao, Shao t m, Wen Shizhu. Study of relative humidity influence on material surface adhesion force [J]. Tribology, 2006, 26 (4): 295-299. 
[14] Wu Jiangang, Yue Ruifeng, Ceng Xuefeng, et al. Micro droplet driving chip based on the principle of electro wetting on the medium [J]. Journal of Tsinghua University, 2006, 46 (7): 1341-1344.

[15] Ding Yingtao, Yao Zhaohui, he Feng. Study on the characteristics of gas flowing in micro nozzle [J]. engineering mechanics, 2004, 21 (3): 190-195

[16] Xie Haibo, Fu Xin, Yang Huayong, et al. Simulation and micro-PIV research on classical micro channel flow [J]. Journal of mechanical engineering, 2006, 42 (5): 32-38.

[17] ZHANG Zhongqiang, YE Hongfei, LIU Zhen., DING Jianning, et al. Carbon nanotube-based charge-controlled speed-regulating nanoclutch. Journal of Applied Physics, 2012, 111: 114304.

[18] ZHANG Zhongqiang, ZHANG Hongwu, ZHENG Yonggang, WANG Lei, and WANG Jingbao. Gas separation by kinked single-walled carbon nanotubes: Molecular dynamics simulations.Physical Review B, 2008, 78: 035439.

[19] Wang Liding, Zhu Jinkui, Liu Chong, Luo Yi. Research progress of micro nano manufacturing in China [J]. Journal of mechanical engineering, 2008, 44 (11): 1-12 